\title{
"humanidades
}

Revista Humanidades

ISSN: 2215-3934

humanidades@ucr.ac.cr

Universidad de Costa Rica

Costa Rica

\section{Clamor de Gaia: violencia, ecología y mito en Claribel Alegría}

Fernández Zambudio, Dra. Josefa

Clamor de Gaia: violencia, ecología y mito en Claribel Alegría

Revista Humanidades, vol. 11, núm. 1, 2021

Universidad de Costa Rica, Costa Rica

Disponible en: http://www.redalyc.org/articulo.oa?id=498064330012

DOl: https://doi.org/10.15517/h.v11i1.45067

\section{(c) $(1) \Theta$}

Esta obra está bajo una Licencia Creative Commons Atribución-NoComercial-SinDerivar 3.0 Internacional. 
Desde el arte, la literatura y la comunicación

\section{Clamor de Gaia: violencia, ecología y mito en Claribel Alegría}

Clamor de Gaia: Violence, Ecology and Myth in Claribel Alegría

Dra. Josefa Fernández Zambudio

Universidad de Murcia, España

pepifz@um.es

DOI: https://doi.org/10.15517/h.v11i1.45067

Redalyc: http://www.redalyc.org/articulo.oa?

iD https://orcid.org/ 0000-0002-2201-2921

$\mathrm{id}=498064330012$

Recepción: 20 Octubre 2020

Aprobación: 18 Diciembre 2020

\section{Resumen:}

En este artículo, se develan las claves de cómo se acerca Claribel Alegría en su poesía a la destrucción de la naturaleza por los hombres y de los hombres entre sí, como especificaciones de los modos de violencia. Para ello, se hananalizado los versos en los que se han desarrollado estos temas, para señalar qué imágenes ha utilizado y en qué contextos ha expresado su preocupación, profundizando en su aproximación a través de algunos mitos pertenecientes a la tradición grecolatina. Estos le permiten explorar diversas perspectivas que abarcan desde la advertencia hasta la esperanza del cambio, gracias a diferentes metáforas y técnicas de representación. Se demuestra que la visión poética sobre la preocupación por cómo nos relacionamos entre nosotros y con nuestro entorno se consigue gracias al distanciamiento proporcionado por las representaciones de los personajes mitológicos.

Palabras clave: Violencia, ecología, poesía, mitología.

\section{Abstract:}

In this paper, are shown the keys to the ways that Claribel Alegría approaches in her poetry the destruction of nature by men and of men among themselves, as specifications of the modes of violence. Here, will be analyzed the verses where these themes have been developed, in order to show which images, she has used and in which contexts she has expressed her concern, deepening his approach through some myths of the Greco-Roman tradition. These allow her to explore diverse perspectives, ranging from warning to hope for change, thanks to different metaphors and techniques of representation. It is shown that the poetic vision about the concern on how we connect with other people and with our environment is achieved thanks to the distancing provided by mythological character representations.

KEYWORDS: Violence, ecology, poetry, mythology.

\section{INTRODUCCIÓN}

La conciencia ecológica en Claribel Alegría (1924-2018) está relacionada con su compromiso social, así como con su preocupación por situaciones de violencia e injusticia. A pesar de esto, no se autodefine como poeta social. En este sentido, en múltiples ocasiones, ha reivindicado el hecho de que la poesía no debe supeditarse a ninguna otra consideración: "Es muy tremendo decir poesía comprometida porque la poesía yo no la quiero poner al servicio de nada. Pero primero que poeta soy ser humano, y como ser humano no me puedo desligar de mis semejantes" (Huete, 2015, párr. 7). Así, desde este punto de vista, la poesía expresa, entonces, una preocupación íntima basada en dos convicciones: la primera, es necesario que el poeta sea bumano y, la segunda, el trabajo con el lenguaje no puede convertirse en excusa para romper el vínculo con la realidad.

De lo anterior surgen los versos que concluyen que la destrucción del medio se vincula con la destrucción del hombre a manos del hombre. Se trata de un mundo de violencia que está especialmente presente en sus orígenes hispanoamericanos, en esos lugares a los que volvió junto a su esposo Bud, Darwin Flakoll, para dar voz a quien no la tenía. Trataron este tema desde los testimonios que recogían; así, son representativos los títulos Nicaragua, la revolución sandinista (Alegría y Flakoll, 1982), No me agarran viva: la mujer salvadoreña en lucha (Alegría y Flakoll, 1983), Para romper el silencio: resistencia y lucha en las cárceles salvadoreñas 
(Alegría y Flakoll, 1984), Fuga de Canto Grande (sobre la fuga de un grupo del Movimiento Revolucionario Túpac Amaru (MRTA), de una cárcel peruana de máxima seguridad [Alegría y Flakoll, 1992]), Somoza, expediente cerrado (Alegría y Flakoll, 1993). Algunos estudiosos se han ocupado de estas obras (Boschetto, 1994; Ferro, 2005), pero aún queda por analizar cómo se ha manifestado este mundo de violencia en la poesía y, específicamente, a través del lente de la mitología.

Siguiendo con lo anterior, en la mitología grecolatina existen numerosos ejemplos de cómo los protagonistas no se tratan de una manera adecuada, desde el terrible Saturno que devora a sus hijos hasta Agamenón, el padre que sacrifica a su hija. En las próximas páginas se describe la forma en la que el dios Hades rapta a su sobrina Perséfone y la tierra se lamenta por las acciones humanas. Estas situaciones son paralelas a los sucesos violentos que Alegría narra en sus obras.

El acercamiento que se propone aquí está justificado desde diversos puntos de vista. En cuanto a violencia y literatura, existe un diálogo histórico que se despliega desde la Antigüedad hasta el presente; desde los poemas homéricos y la tragedia griega clásica hasta la recepción literaria de las guerras del siglo XX, presentes dentro de la memoria colectiva y que, recientemente, ha sido retomado por Saravia y Featherston (2019). El maltrato físico y psicológico al que han debido enfrentarse las mujeres en los países latinoamericanos, así como la falta de dignidad en sus relaciones con los hombres han llevado a una reflexión literaria específica, pues, como señala Teresa Basile (2015), cabe interrogarse sobre "los modos y las retóricas de narrar las experiencias extremas de la historia latinoamericana reciente, las torsiones y torceduras que la violencia ejerce sobre la escritura literaria" (p. 9). Así como se tejen relaciones entre literatura y violencia, hay también un sistema de relaciones entre literatura y medio ambiente que posee un largo recorrido, incluso, puede perfilarse a través de algunos hitos. Las humanidades ambientales demuestran la necesidad de que la cultura reflexione sobre este momento crucial en el que es preciso establecer una nueva relación con el medio ambiente (Albelda, J., Parreño, J.M. y Marrero, J. 2019). En este marco, se concreta en la noción de ecocritica (Glotfelty y Fromm, 1996, p. 18) o, mejor, de ecocriticas (Flys, Marrero y Barella, 2010), pues exige múltiples perspectivas y metodologías, como corresponde a su naturaleza transdisciplinar.

Ahora bien, a pesar de tener un origen anglosajón, estos acercamientos han sido bien recibidos por la literatura hispanoamericana y se han asentado en ella con la construcción de un canon y unas formulaciones teóricas, no sin ciertas dificultades que Jennifer French ha expuesto con habilidad y que demuestran la necesidad de ampliar miras y utilizar metodologías híbridas (French, 2014). Entornos geopolíticos específicos y sus correspondientes transformaciones conducen a una epistemología y búsqueda de identidad que se pueden delimitar a través de la producción literaria en un entorno (Last, 2015, p. 56). Ahora bien, ¿cuál sería el entorno de Claribel Alegría? Los poemas que se recogen fueron compuestos desde su paraíso de Deiá, en Mallorca, pero, como bien ha expresado María Del Pilar Ríos (2018):

Su "matria" (El Salvador), su "patria" (Nicaragua) y los múltiples lugares en los que vivió fueron la fuente de la que se nutre su obra. Sus textos son la expresión más profunda de sus sentires, su historia, sus pérdidas pérdidas personales y su compromiso social con las realidades de opresión de nuestra América Latina y de su Centroamérica en particular (p. 15).

De esta manera, aunque sea de un modo personal y desde la distancia, la identificación con la naturaleza del yo lírico se inserta en la tradición que ha partido de esa identificación para crear un sentimiento nacionalista (Paravisini, 2008, p. 9). Por tanto, está justificado que Steven White la incluya en la nómina de los poetas nicaragüenses (White, 2011), sin que este vínculo agote los acercamientos posibles y, sobre todo, sin que su lectura, por falta de espacio otorgado y por falta de profundidad en sus concepciones, sea comparable a la que aquí se ofrece. Por otra parte, si ya la bibliografía en torno a esta autora no es abundante (Guerrero, 2017, pp. 89-93), mucho menos se encuentran nociones sobre este tema específico. Castellón (2012) menciona que es la amistad su única autoridad para definir a la autora como espíritu del bosque, y su aportación parte más de la sensibilidad y la emoción que del análisis de la obra (p. 35). 
A partir de la encrucijada entre literatura y entorno no solo surgen las interrogaciones sobre la destrucción de la naturaleza (que puede desembocar en la propia destrucción humana) y sobre las estructuras que han hecho posible ese proceso (cf. Heffes, 2013; Yepes, 2014), sino que también se producen reflexiones acerca de qué implican los fallos del ser humano dentro de su relación con el medio ambiente frente a una posterior vinculación con sus semejantes. La explotación de la mujer relacionada con la explotación del entorno y la visión ecofeminista (Murphy, 1995) completan la recepción literaria de estas nociones que reflejan las preocupaciones sociales de sus autores. La perspectiva transversal de los saberes permite una relectura a partir de parámetros significativos. En este sentido, la intersección entre mitocrítica y ecocriticismo está fundamentada (Martín y Molina. 2018, p. 6) desde los mitos del origen y las cosmogonías hasta el paraíso perdido, pasando por el antropocentrismo o la actitud que busca reemplazar esta visión de mundo por una que se decante más hacia el equilibrio con el entorno. A pesar del interés de Claribel Alegría de que se ejecute una lectura tomando en consideración este punto de vista, hasta ahora eso no se ha hecho.

A partir de todo lo anterior, en este trabajo se indaga cuál es la profundidad de su conocimiento acerca de los detalles míticos. Se demuestra cómo el mito le permite poetizar, en primer lugar, su preocupación por la violencia; en segundo lugar, cómo explora diversas perspectivas a partir del componente mítico, concretadas con imágenes poéticas específicas; $y$, en tercer lugar, cuál es la relevancia de la mitología grecolatina dentro del tratamiento de estos temas, esto es, qué aportan los monólogos dramáticos de personajes míticos (cf. Guerrero, 2017; Chen, 2017, p. 76).

\section{VIOLENCIA Y VIOLENCIAS}

La preocupación por el fenómeno de la violencia no solo se ha expresado en la prosa (principalmente en el testimonio), también puede rastrearse en la poesía. De esta forma, el yo lírico en los poemas de Claribel se dirige a una niña y recuerda en Desde el puente: "Sentías horror por la violencia" (Alegría, 1989, p. 25). Como bien recoge Gondouin (2014), a propósito de este poema: "Hay entonces en el autorretrato ensombrecido de la poeta en Desde el puente algo de la desesperanza que le inspiran las guerras, la violencia política y la injusticia social, en su país y en el mundo" (Gondouin, 2014, párr. 15). Así, ante esa niña que presenció la matanza de Izalco con siete años, el yo lírico se pregunta: “Cómo podré explicarte / que no ha cambiado nada / y que siguen matando diariamente?” (Alegría, 1989, p. 25). Este tipo de referencias se convertirán en una constante durante toda su obra, incluso, en su último libro: Amor sin fin, en el cual, frente a la búsqueda de la paz, el yo lírico encuentra su imposibilidad: "Silenciosos los árboles / que ahora me rodean / mas les falta la paz / ¿cómo encontrarla / si en el mundo reina / la violencia?” (Alegría, 2016, p. 41).

Ahora bien, lo que interesa aquí es la forma en la que esta noción general de la violencia se va concretando hasta convertirse en versos. Dichos versos retoman cada una de las situaciones violentas, así como a las personas que las sufren y, además, la naturaleza que las padece. En este sentido, Claribel Alegría va destilando detalles: los “árboles negros”, la "ausencia del mar” y esos “árboles silenciosos” demuestran la desconexión y la falta de diálogo con el entorno. Ejemplo de esta poética consciente de la depredación de la naturaleza es Ecología (Alegría, 1978, p. 34), donde se propone la imagen de un pescador con su familia, en dicha estampa se imbrican un antes y un después apocalíptico y se constata el fracaso del pueblo que atrapa al individuo en un ambiente luctuoso (Yúdice, 1985, p. 955): “(...) sigue pescando el hombre / el agua está podrida / todos los peces muertos / una tabla se cierra / para atraparme el pie / pido socorro exijo / me hacen burla los niños / con las caras cubiertas / de petróleo y algas" (Alegría, 1978, p. 34).

Ya en 1973 en Canción de cuna para Duncan James el yo lírico le plantea una representación negativa al primer nieto de la autora. En este sentido, le advertía que "No es el mejor momento / de venir al planeta" (Alegría, 1973, p. 23). Así, desde esta mirada poética se observa el deterioro y se percibe la falta de diálogo con un medio ambiente que el hombre destroza. Todo esto, a través de un clamor que alcanza lo personal y que se despliega desde su infancia hasta su poemario de despedida. Los ejemplos anteriores 
permiten ilustrar esa base que sustenta las escrituras que se analizarán posteriormente, las cuales están relacionadas específicamente con monólogos pronunciados por diversos personajes pertenecientes a los mitos grecolatinos. En este sentido, para enfocarse en los personajes míticos, se dejan de lado dos poemas: La mujer del rio Sumpul. Ojo de cuervo. En el primero, una mujer se cubre una herida con hojas y más hojas hasta fusionarse con la naturaleza y conseguir que no la vean durante la matanza que tuvo lugar en 1980. Así, se convertirá en "la madre tierra herida" (Alegría, 1989, p. 23), personificada en esta mujer (Alcantar, 2018, p. 138). En cuanto a Ojo de cuervo, se cierra el poemario Umbrales con un recorrido histórico por diversas matanzas donde tampoco se olvida que "está enferma la tierra" (Alegría, 1996, p. 40). Aunque relevantes y dignos de análisis, quedan fuera de este hilo conductor, puesto que no tienen relación directa con la idea de que existe un nexo entre la violencia hacia la naturaleza y la violencia hacia el hombre que sí resuena significativamente en el corpus aquí elegido.

\section{Clamor y dolor}

Los tres primeros poemas forman parte del libro Mitos y delitos (2008): Ira Demetrae, Pandora y Clamor de Gaia. La composición de este libro tiene ciertas particularidades, ya que algunos poemas habían sido publicados previamente, como los mencionados anteriormente. A pesar de ello, encuentran su lugar definitivo en este poemario. Las vicisitudes de este libro se conocen debido a la autora y a la conservación de carpetas en el archivo de Princeton, en las cuales se recogen en dactilografía los poemas que formarían parte del libro (Balladares, 2014).

Ira Demetrae ya había aparecido en Variaciones en clave de mi (Alegría, 1993), pero ahora adquiere cierta relevancia, porque en todas las versiones de cómo iba a ser compuesto Mitos y delitos aparecía entre los primeros poemas y porque, al final, aparece otro poema con un tema similar: Clamor de Gaia, estableciéndose así un diálogo entre ambos. En Ira Demetrae, la diosa de la agricultura busca a su hija Perséfone, como ya lo hizo en el Himno homérico a Deméter (Richardson, 1974). Se advierte una innovación fundamental en los versos de Alegría (1987): la diosa no solo dejará de cuidar los frutos en los momentos de separación de su hija (lo que es una explicación racionalista del invierno), sino que también promete indiferencia: "les cederé a los machos / el planeta" (Alegría, 2008, p. 14). Se refiere a los hombres como "machos cabríos". Esa enmarcación dentro de la bestialidad es la que les permite raptar a muchachas como Perséfone y que, además, Zeus lo refrende. Desde su queja continuada por esta injusticia que justifica su venganza, el yo lírico detalla cómo será esa destrucción: “(...) regarán manchas negras / en el mar / extinguirán los peces / harán el aire irrespirable / se matarán los hombres / entre sí” (Alegría, 2008, p. 14).

Así, se aprecia la relación de las imágenes con el poema Ecología (Alegría, 1987), a través de la descripción del petróleo en el mar. Asimismo, se evidencia cómo se va configurando una enumeración que culmina con la destrucción del hombre a manos del hombre, propia de la idea de una degeneración progresiva. Dicha idea de la degeneración, parte desde un mundo idílico, primigenio, hasta la época actual. Esto está presente, también, en el mito de las edades del hombre (Díaz, 2019). La lectura es clara: no hay protección divina y esta es la explicación de los males de la tierra que está en manos de bestias, de machos cabríos destructores. Estos versos demuestran la totalidad de esta destrucción. Con sutiles variaciones, el yo lírico habla de los cuatro elementos; después, se vuelve hacia el hombre. La enumeración permite crear una atmósfera opresiva, donde la acumulación de desgracias las multiplica.

La violencia específica contra Perséfone, el rapto ejecutado por su tío (cf. Ovidio, Fastos IV 419-618 y Metamorfosis V 346-671; Claudiano, El rapto de Proserpina), tiene su reflejo en la violencia contra todo: la anécdota se trasciende. En otras palabras, no importan los detalles de la fecunda tradición literaria que la respalda tanto como el aviso ecológico. El rapto y la queja materna se desarrollan hasta llegar al clímax de esta venganza y el mito no se usa por una cuestión estética, en Alegría (2008), se convierte en un relato reinterpretado a partir de la preocupación por la violencia. Como contraparte de esta preocupación, existe 
un último resquicio para la esperanza, un límite para esa destrucción: “(...) hasta que Zeus se arrepienta / de su doble moral / hasta que estés conmigo / todo el año / y decretemos juntas / la primavera eterna” (Alegría, 2008, p. 14).¿Puede haber una restitución? ¿Zeus se arrepentiría? En este caso, se trata de un deseo que brota del yo lírico: la justicia debería reestablecerse, de tal manera que para que exista esa primavera eterna en la que todo vuelve a equilibrarse, primero, el poderoso debería rectificarse.

Si entre los primeros poemas se encuentra Ira Demetrae, y entre los últimos, el Clamor de Gaia (se profundizará más adelante), a mitad del libro se halla Pandora, el cual está dirigido a esa mujer, quien es responsable de destapar una vasija en donde se encontraban todos los males del mundo. El yo lírico, dentro de los poemas, muestra una actitud en la que se coloca de su lado y la libera de la culpa:

Sé que en tu cesta / se revuelven (...) / los boinas verdes / las torturas / los escuadrones de la muerte / tiene úlcera la tierra / una pústula rosa / que supura / arrancamos sus bosques / los quemamos / nos servimos del fuego / para destruir sus bosques / envenenamos ríos / y mares / y hasta el aire (...) / pero en el fondo de tu cesta / aún está verde / la esperanza (Alegría, 2008, p. 53).

Guerra y destrucción de la naturaleza se confirman en esta poética como temas de interés. En este caso, el acercamiento se produce, en primer lugar, a través de una enumeración que recorre el dolor que unos hombres infringen a otros, constatado en "los boinas verdes" así como en "las torturas" o "los escuadrones de la muerte". De la misma manera, resulta específica la referencia a la opresión estadounidense de las bandas paramilitares de guerrilleros en El Salvador. Tras la crudeza de estas referencias, el yo lírico plantea una serie de imágenes que muestran una tierra enferma: "tiene úlcera la tierra / una pústula rosa / que supura" (vv. 6-7). La gravedad de esta enfermedad se va concretando en cada uno de los problemas de la tierra, el mar e, incluso, el aire, con una visión totalizadora de las acciones perniciosas humanas, pues alcanzan tanto a otros hombres como a todos los elementos de su entorno. Esta visión de cada uno de los lugares afectados es paralela a la que se analizó en Ira Demetrae. En este caso, el yo lírico al inicio del poema se coloca junto a Pandora, pero pronto se descubre responsable de la destrucción, esto se enmarca a través del uso de la primera persona del plural. En este entramado lírico, la culpabilidad del hombre, de nuevo, se multiplica gracias a los ejemplos concretos de cómo se produce la violencia contra sí mismo y la violencia contra la naturaleza, ambas conectadas.

En Clamor de Gaia, ya casi al final del poemario de Mitos y delitos (2008), se advierte la queja desgarrada de la propia Tierra (la trascripción adecuada es Gaya, pero se mantiene Gaia porque es la empleada originalmente por la autora. Fernández-Galiano aconseja traducir por “Tierra”; cf. 1961, p. 98). En la carpeta conservada en Princeton se encuentra otra versión donde se titula Monólogo de Gaia (Balladares, 2014, p. 244). En efecto, la Tierra habla en primera persona de sus males y les pide a los hijos que la dañan que la escuchen antes de que sea tarde. El poema, como bien señala White (2011), "ofrece un inequívoco aporte mítico-literario de acusación mediante un relato de otredad certera, sobre todo cuando Gaia, simbolización de la máxima fuerza materna que nos sostiene, exige a toda la humanidad conciencia, respeto, amor y vigilancia” (p. 332).

El tema maternal que se presentaba como motivación para la indiferencia de Deméter, aquí, reaparece desde la queja de la propia destrucción. En este caso, se trata de una advertencia directa. Es decir, es una madre amorosa pero oscura, porque engendra a sus propios destructores. Comienza con una cosmogonía y, a medida que avanza, el poema va recriminando a sus hijos, preguntando: “:por qué?”, describiendo esa destrucción, ese dolor, a través de su cuerpo: “(..) mi piel está cubierta / de surcos abismales / de desiertos de arena / de deshechos. / Mis lágrimas son secas. / Como cuencos vacíos / caerán sus ciudades” (Alegría, 2008, p. 91).

La representación de esto, a través de una mujer que sufre, permite detallar la desertificación por medio de imágenes de heridas en el cuerpo y con ese verso de "mis lágrimas son secas" consigue manifestar el dolor de madre. De esta manera, la corporalidad concreta el componente físico del sufrimiento, de modo que no se trata de un dolor general, desdibujado, sino de una serie compleja de daños, los cuales completan el puzzle de esta visión catastrófica. La advertencia final es clara: "Si en destruirme se empeñan / se destruirán ustedes. / Despierten hijos míos / escuchen mi clamor” (Alegría, 2008, p. 92). 
El discurso como en los poemas analizados anteriormente es el mismo: aniquilar la naturaleza es destruir al ser humano. La maternidad a la que alude Gaia conecta con la perspectiva ecofeminista a la que se hacía referencia en la introducción: una perspectiva femenina puede ser la solución para esa esperanza que, a pesar de todo, conservan Pandora y Alegría, porque el hombre, en general, el "macho cabrío", es violento y la violencia depara irremediablemente la destrucción de todo lo que le rodea. En Ira Demetrae los violadores, con la aquiescencia del poder, socavan el entorno y se destruyen unos a otros; en Clamor de Gaia se halla el grito desesperado de la madre, porque ese cuidado será la diferencia entre la vida y la muerte.

\section{VISIONES DEL FUTURO}

Hay dos aspectos significativos en la poética de Alegría: la urgencia y la visión del futuro. Deméter planteaba un futuro sin su cuidado y, en esa descripción, se revela que se trata del presente (en el que se inscribe al lector), pero deja el resquicio de un futuro más allá, utópico, en el que se restablece "la primavera eterna". Pandora desata la guerra y las pústulas en la tierra, pero deja la esperanza y Gaia advierte sobre un presente que puede suponer un futuro extremo, en el cual se especifica que su destrucción implicará la de sus habitantes. Además de esto, Alegría recupera también las figuras de dos visionarios y sus advertencias para el futuro: Tiresias y Casandra, los cuales toman la palabra en los poemas que llevan su nombre en Soltando amarras (2005). Este es un libro de despedida, de diálogo con la muerte y, sin embargo, vital, embargado por la lucidez del umbral para construir una profecía luminosa. En este contexto, Tiresias y Casandra descubren, una vez más, esa potencia destructora del hombre. La visión de Tiresias es profundamente negativa, mientras que la perspectiva de Casandra, que aparece unos poemas después, supone de nuevo la esperanza. Sin embargo, comparten una misma idea: la necesidad de un cambio total que salve a la tierra enferma y, por tanto, que salve también a la humanidad. El discurso, como se comprueba, es similar al de los poemas de Mitos y delitos (Alegría, 2008) que se analizó en el apartado anterior: "Y recuerdo la tierra / la mutilada tierra / el planeta quemado por los hombres / devastado / saqueado por los hombres / y los hombres destruyéndose / a sí mismos" (Alegría, 2005, pp. 21-22).

La humanidad, una vez más, destruye al planeta y a sí misma. En su ceguera, Tiresias recuerda que ya no se habla de futuro, sino de pasado. Tiresias rememora y la violencia humana es la protagonista de su visión.

Más intensa es la imagen empleada en el poema Casandra, en el cual, en una primera parte, se describe una herida sangrante, al igual que en Pandora se hablaba de una "pústula" y en Clamor de Gaia del cuerpo violentado de la diosa: "El mundo sangra / se desangra frente a mí / lo construyen los hombres / lo destruyen” (Alegría, 2005, p. 62).

Casandra ve lo evidente: el presente, pero también el futuro. Esta vez es explícita la referencia a las edades o las razas del hombre, que suponen una degradación de la vida humana, pero la Casandra de Alegría vaticina una esperanza, paralela a la primavera eterna de Ira Demetrae o a la que aún quedaba en Pandora: "El mundo se transforma / y lleva siglos pariendo una raza nueva. / Gobernará la tierra / y cesarán las guerras / la violencia / los odios / se ensancharán los ríos / y crecerán los mares / y los bosques” (Alegría, 2005, p. 62). Estos versos suponen la reconstrucción de todo aquello que Alegría, a través de sus personajes mitológicos, veía tan negativamente: no solo acabará con la guerra, sino que también traerá una regeneración del agua y de los árboles. La violencia puede tener un fin. No se trata, por tanto, de proponer acciones específicas, sino de salvarlo todo, encontrando de nuevo el equilibrio y el diálogo: el vínculo. Tiresias, a pesar de su ceguera, veía y recordaba las imágenes de destrucción; Casandra, conocedora del futuro, solicita un cambio, una transformación a una raza nueva, que suponga la salvación. Las advertencias, implícitamente, demuestran la urgencia del cambio antes de que sea tarde, antes de que no quede nada que salvar.

Esta idea anterior se retoma en su último poemario, Amor sin fin (2016). Se trata de un recorrido por su vida y poesía, una especie de testamento, en el cual vuelve a sus preocupaciones, a veces, dialogando con su propia obra. Supone también una depuración de los temas tratados, los cuales se vuelven esencias, pequeñas 
visiones que recorren el libro en un enfoque final de la propia vida y las propias preocupaciones, en un balance entre lo que es lo relevante y lo que quedará de ella misma. En esta especie de testamento poético de Claribel Alegría, el yo lírico confiesa: "Siempre he sido temerosa / profetizo engaños / y desastres / y no me cree nadie. / Soy Casandra / me he vuelto de pronto / silenciosa / soy la loba Casandra / y sólo aúllo / y me asombro del mundo / que día a día empeora" (Alegría, 2016, p. 58). Como en el primer poema analizado, Ira Demetrae, también aquí, Alegría se vuelve hacia ese mundo que empeora. Ese presentimiento de lo terrible, que le permite identificarse con Casandra, resulta sugerente porque Casandra, en el poema anteriormente analizado, ha profetizado con la esperanza de que una nueva raza lo reconstruya todo.

De esta manera, se concluye que en estos poemas la autora se propone volver, una y otra vez, sobre una preocupación que la persigue y que los mitos le proporcionan voz o, mejor, voces para ello. Deméter, Gaia, Tiresias y Casandra hablan en primera persona; en Pandora, muestra su empatía con la que ha sido tradicionalmente la mujer culpable de los males. Como bien señala Cuvardic (2016), "el monólogo dramático se construye a partir de unos requisitos formales a los que se une la tensión entre la identificación y el distanciamiento crítico o juicio moral" (pp. 169-170). De modo que se representa a un personaje en una situación crítica concreta que permite la objetivación y la universalización del sentimiento (Pérez, 2007). Claribel Alegría, que tiene un deseo de apartarse de la poesía social, pero que refleja en sus obras sus preocupaciones, demuestra su desagrado por la violencia que la naturaleza sufre a manos del hombre y la encuadra en relación con la violencia que también manifiesta hacia sus semejantes. Mediante el mito, y tomando estas diversas posturas que se han analizado, consigue no solo una visión, sino varias, como si los puntos de vista fueran múltiples, a pesar de las concomitancias entre los diversos acercamientos. De esta manera, se aleja del sentimentalismo para aproximarse a esos actos violentos y esta destreza le otorga una fuerza específica a su discurso.

\section{Conclusiones}

Existen dos impulsos humanos fundamentales: el amor y el odio. El amor se resuelve en protección; el odio, en violencia. Claribel Alegría, finalmente, inclina la balanza hacia la esperanza, pero lo hace desde una mirada consciente, la cual no duda en recorrer los modos de violencia de los que el hombre es capaz. Como constata en el poema Selene: "ninguno alcanza la crueldad del hombre / pero ninguno ama / como él" (Alegría, 2011, p. 59).

Se ha comprobado que no existe una perspectiva única, sino múltiples formas de acercamiento a un mismo objetivo, las cuales dialogan entre sí. Desde representaciones múltiples de diversos personajes, demuestra una visión universal y continua. La violencia preocupa desde lo indeterminado a lo determinado, y para figurarla, resulta útil la mitología. Los mitos son un tamiz que permite la conexión efectiva entre la realidad social que le preocupa y la poesía. Mediante la multiplicidad de voces se va configurando este discurso, cuyas líneas principales se han querido constatar en este artículo.

En primer lugar, la violencia hacia el hombre y la naturaleza recorre toda la obra poética de Alegría, convirtiéndose en un tema al que vuelve con cierta constancia, especial pero no únicamente, en sus últimas composiciones. En segundo lugar, no existe una intención primordial de denuncia, sino de que la poesía comunique lo relevante. En cuanto a las formas que adopta, abarcan desde la alusión a la descripción pormenorizada, en la que se detallan situaciones de violencia concretas, pero siempre están dominadas por ese juego en el que hablan diversos personajes, desde sus voces e historias. El uso de imágenes, a veces, enlazadas con enumeraciones opresivas que sitúan al lector en las consecuencias de la violencia, permite mostrar la amplitud y la profundidad de estas realidades. Las quejas y las predicciones de personajes mitológicos permiten, por una parte, distancia, desde la cual se puede trabajar la palabra poética, y por otra parte, la personalización; gracias al uso de una primera persona que habla, bien porque sea el personaje mitológico el que se expresa, bien porque se dirija a un "tú lírico" constituido por un personaje mitológico con el que se 
muestra empatía, en el caso de Pandora y, por tanto, también identificación. Estos monólogos conectan con el dolor producido por estos sucesos, de modo que la mirada se implica y emociona para dejar brotar el verso. En el fondo de la caja de Pandora, siempre queda la esperanza de unos hombres mejores, de una raza que, en lugar de destruir y destruirse, regenere.

\section{REFERENCIAS BIBLIOGRÁFICAS}

Albelda, J., Parreño, J.M. y Marrero, J. M. (Coords.). (2019). Humanidades ambientales. Pensamiento, arte y relatos para el Siglo de la Gran Prueba. Madrid, España: Ediciones Catarata.

Alcantar, S. (2018). Volcán y lucha social: el símbolo del volcán en Cenizas de Izalco y algunos poemas de Claribel Alegría. Istmo. Revista virtual de estudios literarios y culturales centroamericanos, 36,130-144.

Alegría, C. (1973). Pagaré a cobrar y otros poemas. Barcelona, España: Ocnos.

Alegría, C. (1978). Sobrevivo. La Habana, Cuba: Casa de las Américas.

Alegría, C. (1987). La mujer del río Sumpul. Bogotá, Colombia: Editorial del Museo Rayo.

Alegría, C. (1989). Y este Poema-Río. Managua, Nicaragua: Editorial Nueva Nicaragua.

Alegría, C. (1993). Variaciones en clave de Mí. Madrid, España: Libertarias /Prodhufi.

Alegría, C. (1996). Umbrales. Madrid, España: Visor.

Alegría, C. (2005). Soltando amarras. Madrid, España: Visor.

Alegría, C. (2008). Mitos y delitos. Madrid, España: Visor.

Alegría, C. (2011). Otredad. Madrid, España: Visor.

Alegría, C. (2016). Amor sin fin. Madrid, España: Visor.

Alegría, C. y Flakoll, D. J. (1982).Nicaragua, la revolución sandinista. México: Era.

Alegría, C. y Flakoll, D. J. (1983). No me agarran viva: la mujer salvadoreña en lucha. México: ERA.

Alegría, C. y Flakoll, D. J. (1984). Para romper el silencio: resistencia y lucha en las cárceles salvadoreñas. México: ERA.

Alegría, C. y Flakoll, D. J. (1992). Fuga de Canto Grande. San Salvador, El Salvador: UCA Editores.

Alegría, C. y Flakoll, D. J. (1993). Somoza, expediente cerrado. Managua, Nicaragua: El gato negro.

Balladares, M. A. (2014). Mitos y delitos de Claribel Alegría: una lectura crítico-genética de tres poemas. Revista Iberoamericana, 80(246), 241-254.

Basile, T. (Coord.). (2015). Literatura y violencia en la narrativa latinoamericana reciente. La Plata, Argentina: Universidad Nacional de La Plata.

Boschetto, S. (1994). Awakening Women in Central America: Claribel Alegría's Fictions. En S. Boschetto y M.P. McGowan (Eds.), Claribel Alegria and central american literatura (pp. 97-110). Athens, Estados Unidos: Ohio University Center for International Studies.

Castellón, B. (2012). El espíritu del bosque: sombra y alas en Claribel Alegría. Cuadernos Hispanoamericanos, (740), $35-40$.

Chen, J. (2017). Monólogo dramático e intertextualidad: Claribel Alegría y Ovidio. Káñina, 41(3), 75-88.

Cuvardic, D. (2016). El monólogo dramático en el discurso poético. Káñina, 40(1), 167-182.

Del Pilar, M. (2018). Claribel Alegría, huésped de su tiempo. Telar: Revista del Instituto Interdisciplinario de Estudios Latinoamericanos, 20(1), 14-17.

Díaz, L. (2019). Los hombres de la edad de hierro. Antropología de la Grecia arcaica. Pensamiento al margen: revista digital sobre las ideas politicas, (1), 184-200.

Fernández, M. (1961). La transcripción castellana de los nombres propios griegos. Madrid, España: Sociedad española de Estudios Clásicos.

Ferro, N. (2005). Anatomía no es destino. No me agarran viva. La mujer salvadoreña en la lucha de Claribel Alegría y D. J. Flakoll. Telar: Revista del Instituto Interdisciplinario de Estudios Latinoamericanos, 2(2-3), 99-103. 
Flys, C., Marrero, J. M. y Barella, J. (2010). Ecocríticas. Literatura y medio ambiente. Madrid, España: Iberoamericana Vervuert.

French, J. (2014). Naturaleza y subjetividades en la Ame\#rica Latina colonial: identidades, epistemologi\#as, corporalidades. Revista de Cri\#tica Literaria Latinoamericana, 40(79), 35-56.

Glotfelty, Ch. y Fromm, H. (1996). The Ecocriticism Reader: Landmarks in Literary Ecology. Georgia, Estados Unidos: University of Georgia Press.

Gondouin, S. (2014). De este lado del espejo: cruzando fronteras en Luisa en el país de la realidad (Claribel Alegría, 1997). Cahiers d'études romanes, 28, 167-180.

Guerrero, B. (ed.). (2017). Aunque dure un instante. Salamanca, España: Ediciones Universidad de Salamanca.

Heffes, G. (2013). Políticas de la destrucción. Poéticas de la preservación. Apuntes para una lectura (eco)critica del medio ambiente en América Latina. Rosario, Argentina: Beatriz Viterbo Editora.

Huete, U. (2015). Claribel Alegría: El que quiera conocerme que lea mi poesía. El País. Babelia. Recuperado de http s://elpais.com/cultura/2015/11/05/babelia/1446727013_775954.html.

Last, A. (2015). Fruit of the cyclone: Undoing Geopolitics through Geopoetics. Geoforum, 64, 56-64.

Martín, I. y Molina, F. (2018). Mythology and ecocriticism: a natural encounter introduction. Ecozon@: European Journal of Literature, Culture and Environment, 9(2), 1-7.

Murphy, P. (1995). Literature, Nature, and Other. Ecofeminist Critiques. Nueva York, Estados Unidos: State University of New York.

Paravisini, L. (2008). Endangered Species: Caribbean Ecology and the Discourse of Nation. En L. ParavisinieI. Romero (Ed.),Displacements and Transformations in Caribbean Cultures (pp. 1-8). Gainesville, Estados Unidos: University Press of Florida.

Pérez, R. (2007). El monólogo dramático en la poesía española del XX: ficción y superación del sujeto lírico confesional del Romanticismo. Espéculo: Revista de Estudios Literarios, 36(1).

Richardson, N. J. (1974). The homeric hymn to Demeter. Oxford, Reino Unido: Oxford Clarendon Press.

Saravia, M. I. y Featherston, C. (Coords.). (2019). Expresiones de violencia en la literatura: De Grecia a nuestros días. La Plata, Argentina: Universidad Nacional de La Plata.

White, S. F. (2011).Arando el aire. La ecología en la poesia y la música de Nicaragua. Managua, Nicaragua: 400 Elefantes. Yepes, E. (2014). Derroteros de la ecocrítica en tierras americanas. Latin American Research Review, 49(2), 243-252. Yúdice, G. (1985). Letras de emergencia: Claribel Alegría. Revista Iberoamericana, 51(132-133), 953-964. 